\title{
NEURILEMMOMA OF THE ORBITAL BONES CAUSING EXOPHTHALMOS* ${ }^{\dagger}$
}

\author{
BY \\ ALY MORTADA \\ Ophthalmic Section, Faculty of Medicine, Cairo University, Egypt
}

SIMPLE tumours of the orbital bones are not rare, but they have not been described as a cause of unilateral proptosis. The two following cases are of interest because neurilemmoma of the orbital bones has rarely been reported and because the diagnosis rested on the histological findings.

\section{Case Reports}

In the two cases reported below full examinations showed nothing abnormal except in the $x$ rays of the skull. In both cases the right side of the nose was obstructed by a hard mass, the nasal septum deviated to the left, and there was right proptosis. Orbital exploration through a medial orbital incision revealed thickening and irregularity of the medial and lower orbital bony walls, and a biopsy of the affected bone was then taken.

Case 1, a 22-year-old man (Fig. 1), had slowly developed proptosis of the right eye and right nasal obstruction for the past 15 years. The left eye was normal, with visual acuity 6/9 and normal fundus and field of vision.

The right eye showed lateral proptosis of $23 \mathrm{~mm}$. (left side $16 \mathrm{~mm}$.) and limitation of ocular movements inwards. The fundus was normal and the visual acuity 6/18.

Antero-posterior $x$ ray of the skull (Fig. 2) showed thickening and expansion of the right side of the ethmoid bone extending into the orbit and nasal cavity. The nasal septum deviated to the left. The right maxillary bone was also thickened and expanded. The right maxillary sinus was opaque.

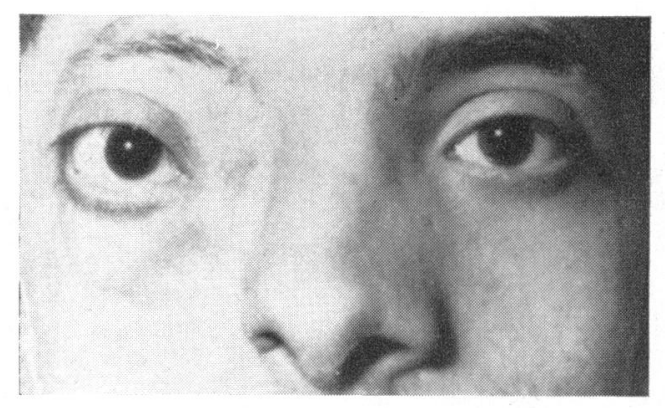

FIG. 1.-Case 1. Right proptosis.

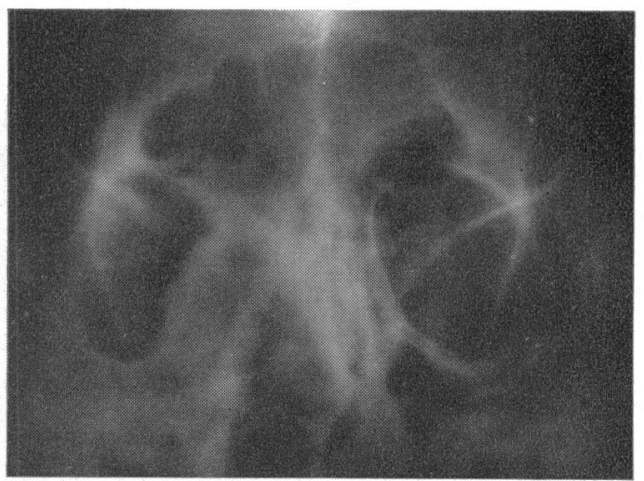

Fig. 2.-Case 1. Antero-posterior skull $x$ ray, showing opacity and expansion of right side of ethmoid and right maxillary bones. The ethmoid bone extends into the right orbit and causes deviation of the nasal septum. The right maxillary antrum is opaque.

* Received for publication December 23, 1966

+ Address for reprints: 18a, 26th July Street, Cairo, Egypt. 
Histopathological examination of a biopsy specimen showed neurilemmoma of the ethmoid and maxillary bones (Fig. 3). The tumour was removed and was found to be composed of spindleshaped Schwann cells with elongated nuclei showing characteristic palisading. Between the cells there was an abundance of long, slender, straight or serpentine reticulum fibres (Fig. 4) of Antoni type A. Some areas showed loosely meshed oedematous areas of degeneration with microcystic spaces constituting the Antoni type B tissue (Fig. 5). There were no nerve fibres.

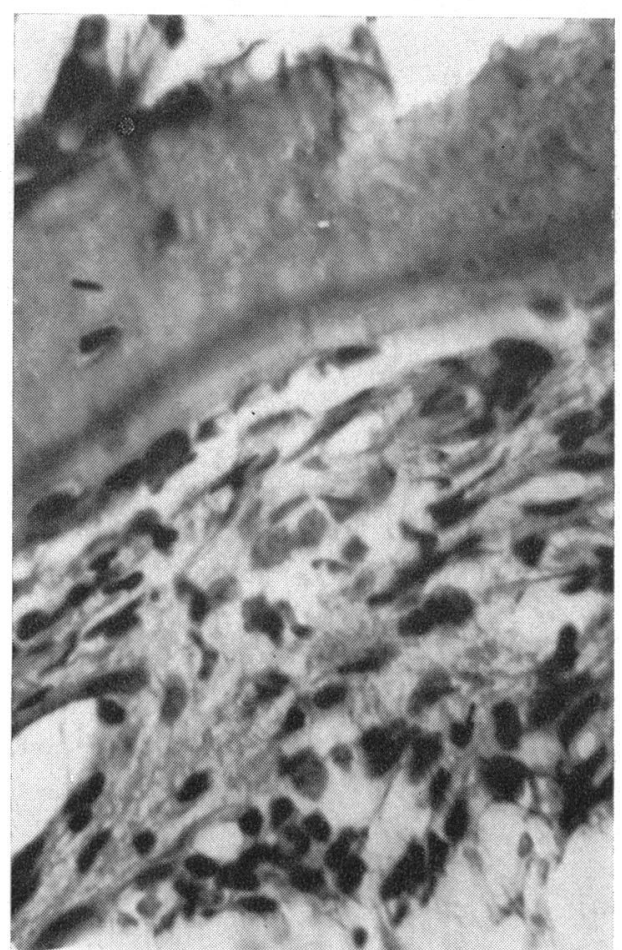

FIG. 3.-Case 1. Neurilemmoma of the orbital bones. $\times 540$.

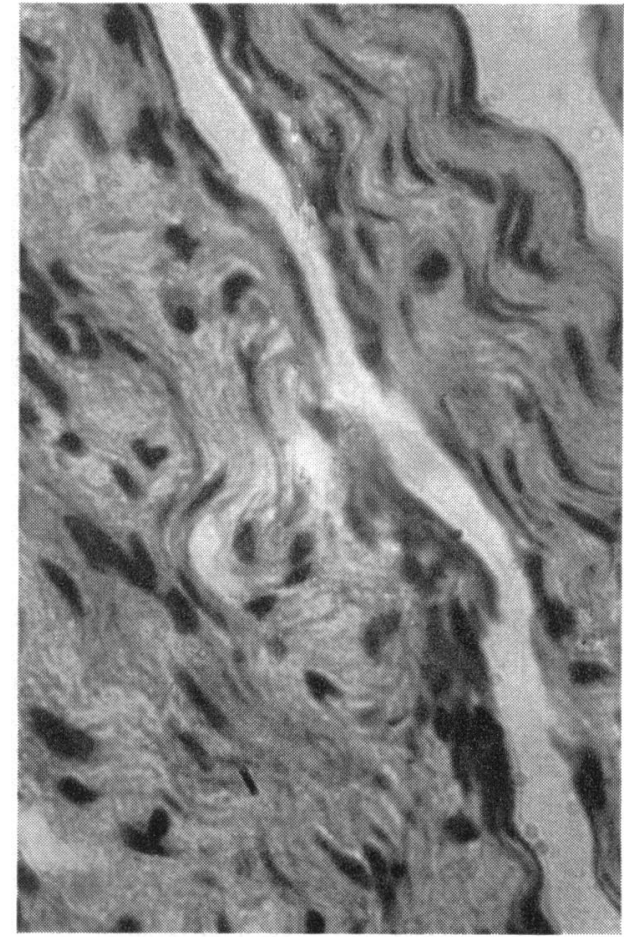

FIG. 4.-Case 1. Spindle-shaped Schwann cells with palisading of nuclei. $\times 540$.

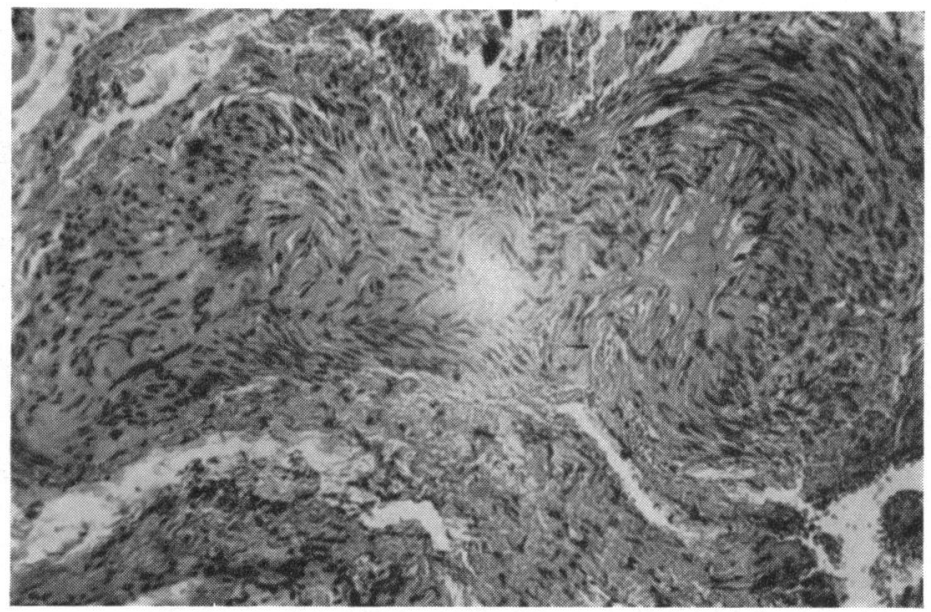

Fig. 5.-Case 1. Areas of degenerative microcystic spaces. $\times 120$. 
Case 2, a 19-year-old girl, had gradually developed proptosis of the right eye for the past 5 years (Fig. 6). The left eye was normal, with visual acuity $6 / 6$ and normal fundus.

The right eye showed lateral proptosis of $25 \mathrm{~mm}$. (left side $15 \mathrm{~mm}$.) and limitation of ocular movements inwards. The fundus was normal and the visual acuity 6/9.

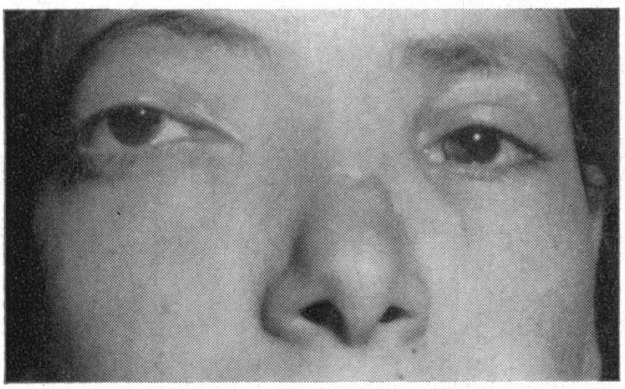

FIG. 6.-Case 2. Right proptosis.

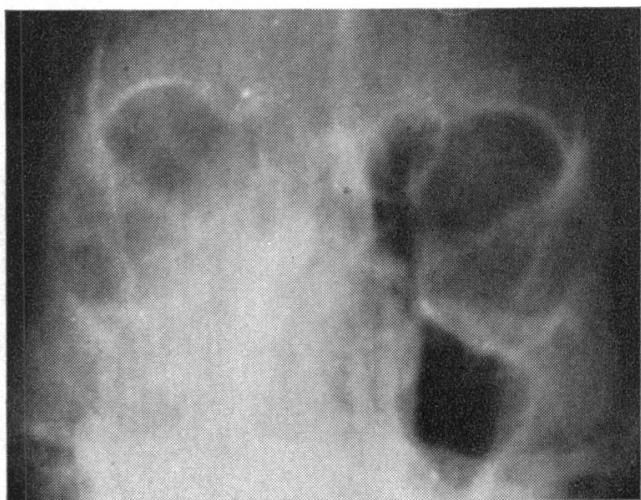

Fig. 7.-Case 2. Antero-posterior skull $x$ ray, showing dense shadow cast by the right side of the ethmoid and right maxillary bones. The nasal septum is deviated to the left. The right maxillary antrum is opaque.

Antero-posterior $x$ ray of the skull (Fig. 7) showed dense opacity of the expanded right side of the ethmoid and right maxillary bones. Attached to the fragments of bone removed for biopsy was greyish-pink tumour tissue. Histopathological examination revealed neurilemmoma of the ethmoid and maxillary bones (Fig. 8, opposite). The tumour was removed and was found to be composed mainly of spindle-shaped cellular fibrillar tissue of Antoni type A (Fig. 9, opposite). The tumour did not contain nerve fibres.

\section{Discussion}

Neurilemmoma of the orbital bones has rarely been reported in the literature, though some cases in other bones have been described: ulna (Peers, 1934: De Santo and Burgess, 1940); humerus (Gross, Bailey, and Jacox, 1939); mandible (Schroff, 1945); patella and sacrum (Jaffe, 1958a).

A neurilemmoma of bone may appear as a clear-cut shadow often bordered by a thin zone of sclerosis or as a multiloculated shadow invading the cranial cavity and even penetrating the cortex in some areas. The diagnosis is usually based on a biopsy (Jaffe, 1958b).

Neurofibroma of bone is rare (Herbut, 1959). The lesion may occur as a solitary mass or in conjunction with neurofibromatosis (Mackenzie, 1950), and the tumour may undergo sarcomatous transformation. Hartmann and Gilles (1959a) described four types of cranial bone change in neurofibromatosis: absence of bone, erosion of bone, cyst formation in bone, and circumscribed lesions resulting from neoplastic invasion.

In skull $x$ rays, shadows of bony changes due to neurilemmoma have to be distinguished from those due to metastasis, fibrous dysplasia, and other simple and malignant tumours of bone. Whether the replacement tissue tends towards ossification or fibrosis, the lesions of fibrous dysplasia of bone do not tend to penetrate the cortex. Fibrous dysplasia of bone usually involves a family history, endocrine disturbance, and/or skin pigmentation. In cases of bone metastasis, $x$ rays may show osteoblastic or osteolytic lesions (Hartmann 


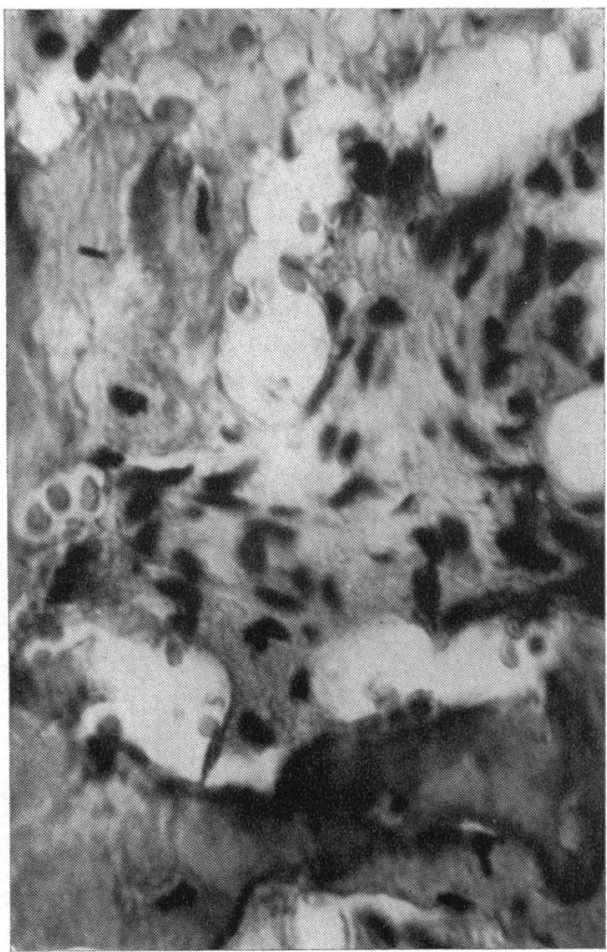

Fig. 8.-Case 2. Neurilemmoma of orbital bones. $\times 540$.

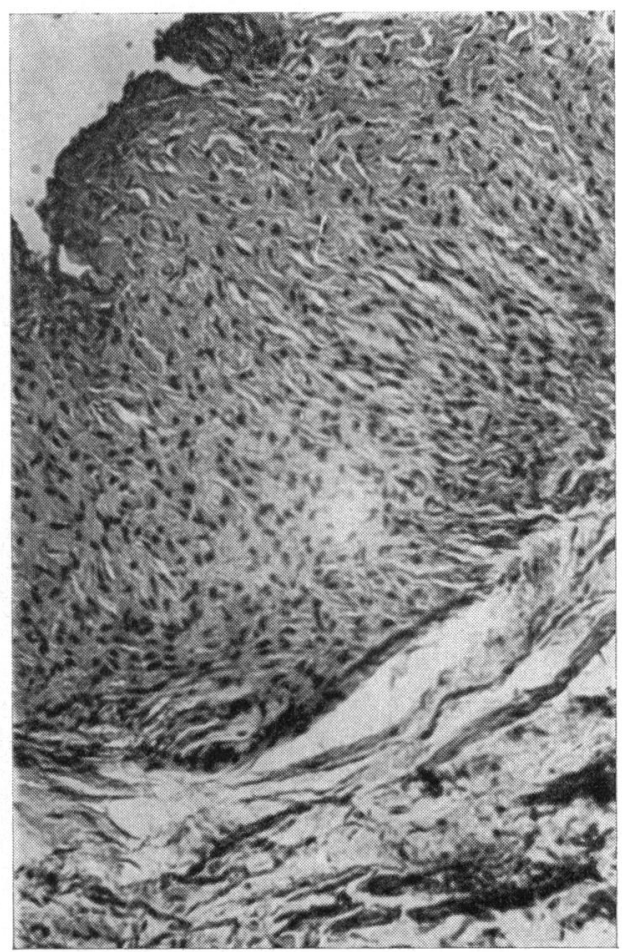

Fig. 9.-Case 2. Spindle-shaped cells with palisading of nuclei. $\times 120$.

and Gilles, 1959b). Primary malignant tumours of the orbital bones, such as osteogenic sarcoma and chondrosarcoma, are rare. Other bony tumours are simple neoplasms, leukaemic infiltrations, reticulo-endotheliosis (eosinophilic granuloma), or bone reaction to sphenoidal ridge meningioma. Among my 500 cases of proptosis there were five due to simple tumours of bone: two cases of fibrous dysplasia (Mortada, 1961), two of neurilemmoma, and one of haemangioma (Mortada, 1964).

Unilateral proptosis due to simple bone tumours usually shows the following characteristics: no external orbital mass; skull $x$ rays suggestive but not diagnostic (bone expansion, sclerosis, or reduction in density); thickening of the affected orbital bones with localized areas of protrusion found on exploration; diagnosis depending on biopsy.

In the early stages a neurilemmoma of the orbital bones usually presents as "proptosis of unexplained origin" (Mortada, 1963, 1965).

\section{Summary}

(1) Neurilemmoma of the right side of the ethmoid and right maxillary bones caused unilateral proptosis in a man aged 22 and a girl aged 19 years. These are the first two such cases to be described from Egypt.

(2) The skull $x$ rays were suggestive, but only biopsy of the affected bones revealed the true nature of the lesions.

(3) Characteristics of simple tumours of the orbital bones causing unilateral proptosis are discussed. 


\section{REFERENCES}

De Santo, D. A., and Burgess, E. (1940). Surg. Gynec. Obstet., 71, 454.

Gross, P., Bailey, F. R., and JACox, H. W. (1939). Arch. Path., 28, 716.

Hartmann, E., and Gilles, E. (1959a). "Roentgenologic Diagnosis in Ophthalmology", trans. G. Z Carter, ed. C. Berens, p. 321. Lippincott, Philadelphia.

-

Herbut, P. A. (1959). "Pathology", 2nd ed., p. $1248 . \quad$ Kimpton, London.

JAFF, H. L. (1958a). "Tumors and Tumorous Conditions of the Bones and Joints", p. 240. Lea and Febiger, Philadelphia. (1958b). Idem, p. 241.

MACKenZIE, J. (1950). Brit. J. Radiol, 23, 667.

MortadA, A. (1961). Brit. J. Ophthal., 45, 737. (1963). Ibid., 47, 445.

(1964). Amer. J. Ophthal., 57, 270.

(1965). Brit. J. Ophthal., 49, 547.

Peers, J. H. (1934). Amer. J. Path., 10, 811.

SChroff, J. (1945). J. Amer. dent. Ass., 32, 199. 